Landslides (2019) 16:1

DOI 10.1007/s10346-018-1120-z

Received: 4 December 2018

Accepted: 5 December 2018

Published online: 19 December 2018

(c) Springer-Verlag GmbH Germany

part of Springer Nature 2018

\section{Foreword by Flavia Schlegel for the Journal of the International Consortium on Landslides}

Disasters induced by natural or man-made hazards affect millions of people every year worldwide. The resulting loss of life is tragic, highlighting the vulnerabilities all societies share.

During the summer of 2018, we have witnessed again the devastating impacts of natural hazards-including landslides-around the globe. The State of Kerala in India has suffered from the worst flooding since 1924, causing severe landslides, resulting in 445 casualties, and more than 200,000 people who needed to evacuate. In Japan, 220 people were killed in July by torrential rains causing large flooding and landslides. In September, Japan was hit by a powerful earthquake that triggered hundreds of landslides destroying infrastructure and killing dozens of people. During the same period, typhoon Mangkhut caused landslides, damage to buildings and homes, and loss of power in the Philippines. In Uganda, the River Suume burst its banks after torrential rains, triggering landslides that devastated two villages. These are only a few examples of the catastrophic impact of landslides.

UNESCO has been a catalyst for international, interdisciplinary cooperation in many aspects of disaster risk reduction and mitigation, in collaboration with both UN Agencies and other scientific entities. Through the interface of education, natural and social sciences, culture and communication and information, UNESCO supports Member States to implement the Sendai Framework for Disaster Risk Reduction, which is in line with the 2030 Agenda for Sustainable Development and the Paris Climate Agreement.

In the domain of landslide hazard, UNESCO actively supports The International Consortium on Landslides (ICL) that has made steady progress on cooperative research and capacity building in landslide risk mitigation. The knowledge and experience acquired over the past years through the Consortium, led by Professor Kyoji Sassa, Chairman of ICL, represents a success story of international scientific cooperation.

Since the establishment of the Consortium in 2002, UNESCO actively participates in its various activities. Among the recent activities, there is the initiative of identifying World Centres of Excellence (WCoEs) on Landslide Risk Reduction, introduced in the 2006 Tokyo Action Plan by the IPL Global Promotion Committee. WCoEs are identified at the World Landslide Forum organized every 3 years within eligible organizations, such as universities, institutions, NGOs, government ministries and local governments, contributing to "Risk Reduction for Landslides and Related Earth System Disasters".
It was a pleasure for me to support the publication of major UNISDR-ICL Landslide Interactive Teaching Tools (LITT) that was launched in 2017. This interactive teaching toolkit will help support academics, leading engineers and practitioners to formulate necessary capacities and technical training for landslide disaster risk reduction.

UNESCO supports the publication Landslides: Journal of the International Consortium on Landslides through its Editorial and Advisory Boards. UNESCO congratulates ICL for publishing more regularly its journals since the Consortium is receiving more technical articles on landslide risk assessment and risk reduction. I expect that this journal will help practitioners to further advance landslide disaster risk reduction.

I look forward to an enhanced collaboration in future activities and undertakings.

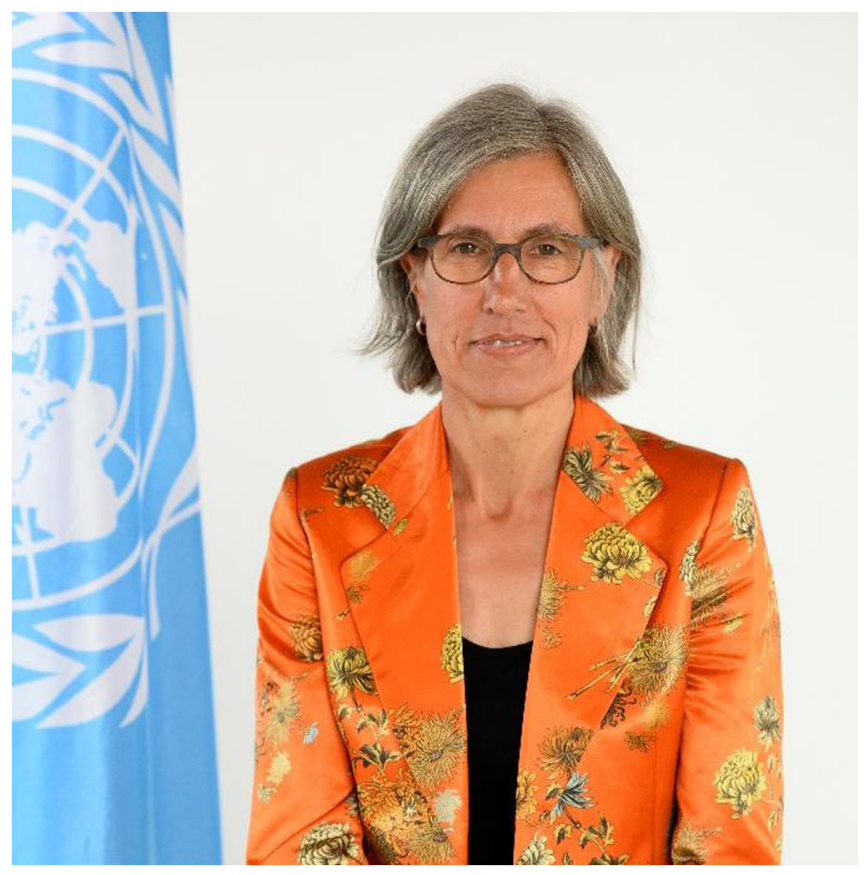

Flavia Schlegel

Assistant Director-General for Natural Sciences UNESCO 